\title{
Continual updating and monitoring of clinical prediction models: time for dynamic prediction systems?
}

David A. Jenkins ${ }^{1,2^{*}}$, Glen P. Martin ${ }^{1}$, Matthew Sperrin ${ }^{1}$, Richard D. Riley ${ }^{3}$, Thomas P. A. Debray ${ }^{4}$, Gary S. Collins ${ }^{5}$ and Niels Peek ${ }^{1,2,6}$

\begin{abstract}
Clinical prediction models (CPMs) have become fundamental for risk stratification across healthcare. The CPM pipeline (development, validation, deployment, and impact assessment) is commonly viewed as a one-time activity, with model updating rarely considered and done in a somewhat ad hoc manner. This fails to address the fact that the performance of a CPM worsens over time as natural changes in populations and care pathways occur. CPMs need constant surveillance to maintain adequate predictive performance. Rather than reactively updating a developed CPM once evidence of deteriorated performance accumulates, it is possible to proactively adapt CPMs whenever new data becomes available. Approaches for validation then need to be changed accordingly, making validation a continuous rather than a discrete effort. As such, "living" (dynamic) CPMs represent a paradigm shift, where the analytical methods dynamically generate updated versions of a model through time; one then needs to validate the system rather than each subsequent model revision.
\end{abstract}

Keywords: Clinical prediction models, Dynamic model, Validation, Model updating, Model development, Learning health system

\section{Background}

Clinical prediction models (CPMs) are tools that compute the risk of an outcome given a set of patient characteristics ("predictors"), and can be used for informing diagnosis or prognosis in individuals [1,2]. They are typically based on multivariable regression models, for example as derived by analysing historical cohort data or routinely collected healthcare data. Arising from the desire to move health systems away from managing or curing disease towards preventative medicine, CPMs have become popular and several are now embedded in

\footnotetext{
* Correspondence: david.jenkins-5@manchester.ac.uk

'Division of Informatics, Imaging and Data Science, Faculty of Biology, Medicine and Health, The University of Manchester, Manchester Academic Health Science Centre, Manchester, UK

${ }^{2} \mathrm{NIHR}$ Greater Manchester Patient Safety Translational Research Centre, The University of Manchester, Manchester, UK

Full list of author information is available at the end of the article
}

clinical practice (e.g. QRISK3 [3] and the Leicester diabetes risk score [4]).

Commonly, the process of developing a CPM equation is a one-time activity, with estimates of model parameters obtained from a single dataset ignoring time. Once a model has been developed, usually the model equation remains fixed until a revision is conducted. However, revisions are rare and usually undertaken at an arbitrary time, or following an external validation that suggests the model is miscalibrated. Model validation is an important aspect of the CPM pipeline and aims to evaluate whether model predictions are accurate (in settings they would be applied to in practice). Similarly to model development, validation is often a one-time activity. Commonly, the literature refers to CPMs as being "validated", but this may create a false impression that no more model testing needs to be performed. In this paper, we propose moving away from one-time model development and validation, and rather

(c) The Author(s). 2021 Open Access This article is licensed under a Creative Commons Attribution 4.0 International License, which permits use, sharing, adaptation, distribution and reproduction in any medium or format, as long as you give appropriate credit to the original author(s) and the source, provide a link to the Creative Commons licence, and indicate if changes were made. The images or other third party material in this article are included in the article's Creative Commons licence, unless indicated otherwise in a credit line to the material. If material is not included in the article's Creative Commons licence and your intended use is not permitted by statutory regulation or exceeds the permitted use, you will need to obtain permission directly from the copyright holder. To view a copy of this licence, visit http://creativecommons.org/licenses/by/4.0/. 
embed CPM development, validation, and updating into a dynamic system that reflects an evolving healthcare service. For example, the current COVID-19 pandemic represents a situation where this would be particularly useful, given how quickly healthcare processes have changed, meaning that any prediction models for COVID-19 need to be updated rapidly $[5,6]$. For example, in the future, vaccinations, immunity build up, and virus mutation may affect the strength of predictor effects over time.

\section{Calibration drift prediction problem}

CPM production pipelines are built on the assumption that once produced and verified, evidence can be translated into practice ad infinitum. But the distribution of patient characteristics, disease prevalence, and health policies change over time. When these changes occur, the estimated CPM parameters and corresponding predictions may no longer be valid $[7,8]$. Consequently, the agreement between the observed and predicted event rates worsens over time [9]: the so-called calibration drift [10]. Hickey et al. [8] highlight this issue in the logistic EuroSCORE model [11], which quickly became outdated as improvements in patient outcomes were rapid. Therefore, there is evidence that model coefficients need to change through time, as illustrated with EuroSCORE. In addition, Luijken et al. [12] observed that changing predictor measurement procedures induced miscalibration in nine real-world examples.

Traditional practice to address this is to develop another CPM de novo. However, alternative approaches, such as updating [13, 14], aggregating existing CPMs $[15,16]$, or meta-analysis of individual participant data $[17,18]$, are preferable because they do not discard historical data and previous research efforts [19]. For example, models such as QRISK are now updated yearly $[3,20]$ using contemporary data and also revised to include additional predictors (such as the revision of QRIS K2 [21] into QRISK3 [3]). Nonetheless, this updating (recalibration) is still relatively uncommon, often occurs a substantial time after model development, is often undertaken at arbitrary time points, and is typically dependent on funding. For example, EuroSCORE II [22] was developed in 2012, some 13 years after the original model, and it is unclear when this will be updated again. The problem with this approach to model validation and revision is that predictive performance of a CPM may only be investigated many years after the model has been developed. Although this can subsequently result in the CPM being updated, incorrect decisions may have already been made as a result of the miscalibrated model and harm already caused.

Typically, a model is developed or updated under the assumption that the data are well described by a fixed underlying model where the coefficients are constant across the observation period used to develop the model. If the prevalence of an outcome is increasing at a steady rate during a 5-year window of data collection and then used to develop the model, the CPM will be calibrated to the middle of the window and not the most recent data. The overarching issue here, for both development and validation, is that the data-generating process could change through time. While frequent model updating will mitigate these issues, it does not eliminate the problem since commonly used methods do not acknowledge temporal changes. Rather, we propose embedding prediction models in practice to ensure development, validation, and updating are a continual process. We now discuss how this might be implemented and the challenges involved.

\section{Possible solution and challenges}

The healthcare system and disease populations are constantly changing, but the CPMs we deploy are not updating at the same rate. Therefore, we need to ensure a CPM is maintained on a continual (rather than an ad hoc) basis. For this to be achieved, we need to reduce the latency period between observing calibration drift and updating a model, thus moving towards a service that constantly monitors a model and has an embedded feedback loop where the monitoring information is then relayed back to the model and used to modify and maintain it.

\section{Dynamic models}

Dynamic prediction models have been proposed as a potential solution to calibration drift and to allow prediction models to evolve simultaneously with the healthcare system [23, 24]. They are a collection of analytical methods that allow CPMs to continuously adapt as data on new patients arises-thus reducing the data-action latency compared with traditional methods of developing CPMs at a single point in time. By dynamic model, we mean models that update over calendar time as data on new individuals arises, not models that update predictions for individuals as new data on them arises. A dynamic model is formulated to account for the calendar time that a prediction is made, that is the calendar time predictors are recorded for each individual (e.g. date of GP appointment), and is designed to evolve over time, such that the parameter estimates are not constrained to remain fixed as (calendar) time evolves. Thus, given a fixed set of patient characteristics, a dynamic model could produce different predicted risks at different times of prediction, for example, if two individuals with the same predictor values are observed at different times, then the model could produce different predicted risks.

The simplest approach to develop a dynamic CPM is to include (calendar) time as a predictor [25, 26]. 
Alternatively, the Bayesian dynamic model could be implemented, where information obtained from past data is used as prior information and combined with new data to obtain updated estimates, thereby updating with new observations in real time [23, 24, 27]. More weight can also be given to the most recent data by "forgetting" past data at a given rate. For more detail on these methods, see the reviews by Jenkins et al. [24] and Su et al. [28]. In summary, dynamic models allow us (1) to utilise historical data and models more effectively, (2) to reduce data-action latency (time between changes in the data and reacting to them), and (3) to "automatically" adapt model parameters over time. Hickey et al. [29] illustrate the use of dynamic modelling in EuroSCORE and show how the coefficients change over time.

Although there is much potential in dynamic models, they are rarely used in healthcare. There are both methodological and practical reasons why this is so. Methodological reasons include the following: (1) a lack of methods on how to validate dynamic prediction models [24], (2) uncertainty on when to include new or exclude existing predictors, (3) deciding how much to discount historical data, (4) uncertainty around when to update the model, (5) the potential lack of model transparency, and (6) inconsistent outputs over time (e.g. a patient with the stable risk factors could have changing predicted risks because the model has changed). Practical considerations include the following: (1) lack of robust and suitable new data to be able to update the models continuously, (2) complexity of the dynamic modelling approach, (3) lack of software implementations, (4) lack of requisite expertise by those developing the model, and (5) lack of infrastructure and funding. However, many of these problems are not specific to dynamic CPMs, for example, the problem of how to handle historical data in traditional CPMs is often ignored but a problem is still present. When updating CPMs, we often append the new data to past data or use only the recent data to perform the update. This is an arbitrary choice by the researcher performing the update, and neither is likely to be optimal. Raftery et al. [23] attempted to address this in dynamic modelling by using an approach to choose how to discount past data at each update by optimising the predictive performance over past samples, but this is computationally expensive. More of these challenges have also attempted to be addressed in statistical literature, for example, use of the time dependent AUC [30], but have yet to be applied to continual prognostic modelling. Other theoretical methods to address these challenges also exist, but their application in prognostic model research is generally lacking and it remains unclear how this would and should affect prediction model research.

\section{Model surveillance}

If a dynamic model evolves with every new data point, then there is only ever the next data point in which to validate each evolution of the model. Furthermore, validation at a given time point is only a single snapshot in time. It does not follow that if a CPM, dynamic or otherwise, has high performance at a given point in time that it will always perform well. However, as we continue to make predictions for new patients, we can record and monitor the accuracy, essentially continuously monitoring and testing for calibration drift (prequential testing [31]). This leads to the idea of model surveillance, where the CPM monitoring could be performed after every new data point or at given intervals. Prequential testing approaches have a long history in the statistical literature and have been used in areas such as economic forecasting. However, they have yet to be transported and used in prediction model research. Lenert et al. [32] discuss the notion of having surveillance of models used in practice as the models themselves can directly impact the data and subsequently their own performance. They explain that without surveillance, models will have limited effectiveness and can become hazardous. We propose prequential testing as a potential solution to these issues but further research is required.

\section{Feedback loop}

Model surveillance, and the use of prequential testing, could also allow us to address some of the issues discussed above. However, continuous monitoring of performance will not address all of these problems. The results of continuous monitoring need to be transported back into the model providing a feedback loop, which allows the model to learn and ensures the model continually provides accurate predictions (Fig. 1). Ideally, this would be conducted in a timely manner to reduce the data-action latency, which is a key metric of the learning health system (LHS) [33], a system that improves itself by learning from new data through cyclic processes that mobilise data to create new knowledge and then use that knowledge to improve. We therefore need a system approach, where one encompasses clinical prediction modelling into a learning health system, thus resulting in a learning prediction system. This system could improve itself by learning from data, continually and in real time, and would take place through cyclical processes (Fig. 1).

Minimising the data-action latency, and doing so efficiently, requires concerted data capture, aggregation, and analysis followed swiftly by interpretation of results, assignment of responsibility for any actions, and recording of actions. Not only can a learning prediction system allow a model to evolve over time, but it could also decide when and how to evolve each iteration of the cycle. This is achievable in LHSs that are supported by 

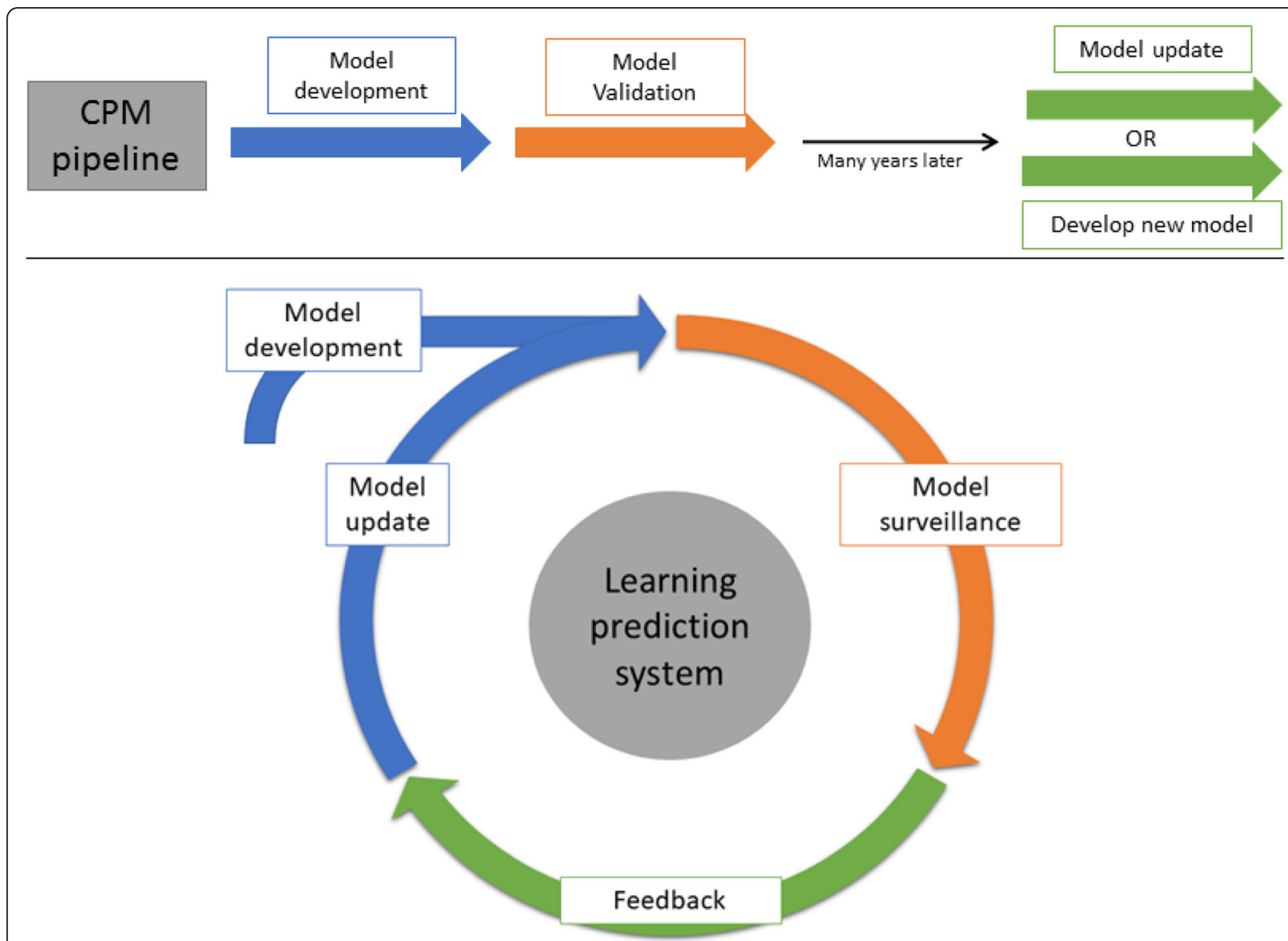

Fig. 1 Illustration of the current CPM pipeline (top) and the proposed learning prediction system (bottom)

infrastructures that enable these processes to take place routinely and with efficiency of scale and scope. Dynamic methods (updating and/or monitoring) offer a flexible solution, requiring less manual labour, but need the infrastructure and sustained resources in place to implement them. Adibi et al. [34] discuss an integrated infrastructure for CPMs and highlight that much of the technology is available, but not yet fully utilised in healthcare. For dynamic updating to work, a system is needed where patient data is automatically collected and stored in a database and subsequently used to update parameter estimates.

\section{Further considerations}

We acknowledge that continually updating a CPM might not always be needed. For example, comparative audit requires a standardised method to adjust for case-mix differences, so dynamic methods might not be appropriate. Also, updating all of the coefficients in a model may not always be a good idea. Booth et al. [35] recently proposed temporal recalibration in settings where survival is improving over time. This approach develops a model using all the available data but then recalibrates the baseline survival function using a subset of the data from a recent time window. Vergouwe et al. [36] described a closed test procedure to select methods for updating prediction models, something which could be embedded into the learning prediction system. This study also found that model revision, updating all model coefficients, can be chosen over intercept-only updating, even in small sample sizes, further supporting the need for a continual system. Although we could redevelop or update traditional models on a daily basis, the use of dynamic methods may offer a more flexible solution. Both traditional and dynamic approaches to CPM development/updating have their advantages and disadvantages (see Table 1), but ultimately, all CPMs need their performance to be monitored regularly and thus require a continual flow of data.

Dynamic CPMs require a continual flow of data. These are typically provided by routine data sources such as audit data, registries, and electronic health records. Dynamic CPMs also offer opportunity in remote monitoring data, such as wearable device or app data, which 
Table 1 Summary of the characteristics and pros and cons for different modelling approaches

\begin{tabular}{|c|c|c|c|}
\hline Models & Characteristics & Advantages & Disadvantages \\
\hline \multicolumn{4}{|l|}{ Existing approaches } \\
\hline Fixed model never updated & $\begin{array}{l}\text { - Model and coefficients } \\
\text { fixed } \\
\text { - Never updated }\end{array}$ & $\begin{array}{l}\text { - Cheap (funding } \\
\text { available) } \\
\text { - Low complexity and } \\
\text { easy to communicate }\end{array}$ & $\begin{array}{l}\text { - Can become miscalibrated quickly } \\
\text { - Dethroned by new model likely } \\
\text { developed in future } \\
\text { - Ends up as research waste } \\
\text { - Loss of information }\end{array}$ \\
\hline Model with ad hoc updating (e.g. EuroSCORE) & $\begin{array}{l}\text { - Updated when } \\
\text { opportunity allows } \\
\text { - Fixed coefficients } \\
\text { between updates }\end{array}$ & $\begin{array}{l}\text { - Easy to maintain } \\
\text { - Cheap (funding } \\
\text { available) } \\
\text { - Low complexity } \\
\text { - Little manual labour } \\
\text { - Advantageous over } \\
\text { developing a } \\
\text { completely new } \\
\text { model }\end{array}$ & $\begin{array}{l}\text { - Non-responsive to calibration drift } \\
\text { - Long data-action latency }\end{array}$ \\
\hline Models that get periodically updated (e.g. QRISK) & $\begin{array}{l}\text { - Fixed regular updates } \\
\text { - Set time period between } \\
\text { updates }\end{array}$ & $\begin{array}{l}\text { - Lower chance of } \\
\text { miscalibration than } \\
\text { above } \\
\text { - Allows predictors to } \\
\text { be included/excluded } \\
\text { from the model } \\
\text { - Relatively low } \\
\text { complexity }\end{array}$ & $\begin{array}{l}\text { - Funding required } \\
\text { - Can still observe calibration drift } \\
\text { between updates } \\
\text { - Increased maintenance } \\
\text { - Requires more than manual labour } \\
\text { to maintain } \\
\text { - Uncertainty on length of time } \\
\text { needed between updates }\end{array}$ \\
\hline \multicolumn{4}{|l|}{ Proposed approaches } \\
\hline $\begin{array}{l}\text { Models with discrete updating and continual } \\
\text { validation/monitoring (learning prediction system with } \\
\text { discrete updating and continual monitoring) }\end{array}$ & $\begin{array}{l}\text { - Updated when } \\
\text { opportunity allows } \\
\text { - Continuously monitors } \\
\text { new data } \\
\text { - Updated as a result of } \\
\text { the monitoring } \\
\text { - Feeds back information } \\
\text { to the model on how } \\
\text { and when to update }\end{array}$ & $\begin{array}{l}\text { - Monitoring informs } \\
\text { updates } \\
\text { - Only update when } \\
\text { required } \\
\text { - Reactive to changes } \\
\text { - Transports well across } \\
\text { settings and } \\
\text { populations }\end{array}$ & $\begin{array}{l}\text { - Funding and infrastructure } \\
\text { required } \\
\text { - Update does not immediately } \\
\text { follow after suggestion from } \\
\text { monitoring } \\
\text { - Requires some manual labour to } \\
\text { maintain }\end{array}$ \\
\hline $\begin{array}{l}\text { Complete dynamic system (continual model update } \\
\text { with continual validation/monitoring) (learning } \\
\text { prediction system with continual updating and } \\
\text { monitoring) }\end{array}$ & $\begin{array}{l}\text { - Dynamic model } \\
\text { - Continuously monitors } \\
\text { new data } \\
\text { - Feeds back information } \\
\text { to the model }\end{array}$ & $\begin{array}{l}\text { - Efficient } \\
\text { - Potential to be more } \\
\text { accurate } \\
\text { - Provides less } \\
\text { miscalibrated results } \\
\text { - "Reacts" quicker to } \\
\text { change (responsive) } \\
\text { - Possible to automate } \\
\text { - Less manual labour } \\
\text { to maintain } \\
\text { - Transports well across } \\
\text { settings and } \\
\text { populations } \\
\text { - Do not need to store } \\
\text { the data }\end{array}$ & $\begin{array}{l}\text { - Requires access to an appropriate } \\
\text { "living" data source that is linked } \\
\text { to the relevant outcomes } \\
\text { - Uncertainty on how one should } \\
\text { validate dynamic prediction } \\
\text { models } \\
\text { - Uncertainty on when to include/ } \\
\text { exclude predictors } \\
\text { - Deciding how much to discount } \\
\text { historical data } \\
\text { - Uncertainty around when to } \\
\text { update the model } \\
\text { - Lack of software packages } \\
\text { - Complexity of approach } \\
\text { - Lack of requisite expertise by } \\
\text { those developing the model } \\
\text { - Lack of transparency } \\
\text { - Inconsistent outputs from day to } \\
\text { day } \\
\text { - Funding }\end{array}$ \\
\hline
\end{tabular}

provides large quantities of data in real time that is otherwise challenging to analyse. However, continuous data flows are usually not supported by epidemiological studies and clinical trials. This could raise concerns about the quality of dynamic CPMs because routine data sources tend to have poorer data quality and higher levels of missingness than study datasets. A possible solution is to develop CPMs using high-quality study data (e.g. from a prospective observational study) and dynamically revise and monitor them using the routine data. However, quality checks and comparisons between the datasets would still be required.

Throughout this article, we have focused on the temporal aspect of miscalibration; however, miscalibration can also occur when CPMs are transferred to different settings and/or populations $[9,37]$. It may be possible to 
generalise the concept of dynamic CPMs to address this type of calibration variation in space. For example, dynamic approaches could be used to tailor a model to a local population or transfer a model to a different setting. This is an area that requires further research.

\section{Conclusion}

Static CPMs are at risk of being always one step behind on reality. Through an alliance between information technology and statistics, clinical prediction can be progressed to a continual service that minimises the dataaction latency in preventative medicine.

\section{Acknowledgements}

Not applicable

\section{Authors' contributions}

We confirm that the manuscript has been read and approved by all named authors and that there are no other persons who satisfied the criteria for authorship. D.A.J wrote the manuscript and contributed to the discussion. G.P.M, M.S, T.P.A.D, R.D.R, G.S.C, and N.P contributed to the discussion and reviewed/edited the manuscript.

\section{Funding}

DAJ's and NP's time is partly funded by the National Institute for Health Research Greater Manchester Patient Safety Translational Research Centre (NIHR Greater Manchester PSTRC). NP's time is partly funded by the NIHR Manchester Biomedical Research Centre (NIHR Manchester BRC). The views expressed are those of the author(s) and not necessarily those of the NHS, the NIHR, or the Department of Health and Social Care. Thomas P.A. Debray was supported by the Netherlands Organization for Scientific Research (91617050) and the European Union's Horizon 2020 Research and Innovation Programme under ReCoDID Grant Agreement No. 825746. GSC was supported by the NIHR Biomedical Research Centre, Oxford, and Cancer Research UK (programme grant: C49297/A27294).

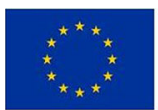

This project has received funding from the European Union's Horizon 2020 research and innovation programme under ReCoDID grant agreement no. 825746.

\section{Availability of data and materials}

Not applicable

\section{Ethics approval and consent to participate}

Not applicable

\section{Consent for publication}

Not applicable

\section{Competing interests}

The authors declare that they have no conflicts of interest relating to the publication of this work.

\section{Author details}

${ }^{1}$ Division of Informatics, Imaging and Data Science, Faculty of Biology, Medicine and Health, The University of Manchester, Manchester Academic Health Science Centre, Manchester, UK. ${ }^{2}$ NIHR Greater Manchester Patient Safety Translational Research Centre, The University of Manchester, Manchester, UK. ${ }^{3}$ Centre for Prognosis Research, School of Primary, Community and Social Care, Keele University, Staffordshire, UK. ${ }^{4}$ Julius Center for Health Sciences and Primary Care, University Medical Center Utrecht, Utrecht University, Utrecht, The Netherlands. ${ }^{5}$ Centre for Statistics in Medicine, Nuffield Department of Orthopaedics, Rheumatology and Musculoskeletal Sciences, University of Oxford, Oxford, UK. ${ }^{6} \mathrm{NIHR}$ Manchester Biomedical Research Centre, The University of Manchester, Manchester Academic Health Science Centre, Manchester, UK.
Received: 14 May 2020 Accepted: 8 December 2020

Published online: 11 January 2021

\section{References}

1. Hemingway $\mathrm{H}$, et al. Prognosis research strategy (PROGRESS) 1: a framework for researching clinical outcomes. BMJ. 2013;346:1-11.

2. Steyerberg $E$, et al. Prognosis research strategy (PROGRESS) 3: prognostic model research. PLoS Med. 2013;10:e1001381.

3. Hippisley-Cox J, Coupland C, Brindle P. Development and validation of QRIS $\mathrm{K} 3$ risk prediction algorithms to estimate future risk of cardiovascular disease: prospective cohort study. BMJ. 2017;357:1-21.

4. Gray $\sqcup$, et al. The Leicester Risk Assessment score for detecting undiagnosed type 2 diabetes and impaired glucose regulation for use in a multiethnic UK setting. Diabet. Med. 2010;27:887-95.

5. Martin, G. P., Sperrin, M. \& Sotgiu, G. Performance of prediction models for covid-19: the caudine forks of the external validation. Eur. Respir. J. 2020; 2003728. doi:https://doi.org/10.1183/13993003.03728-2020.

6. Wynants $L$, et al. Prediction models for diagnosis and prognosis of covid-19: systematic review and critical appraisal. BMJ. 2020;369.

7. Vergouwe Y, Moons KGM, Steyerberg EW. External validity of risk models: use of benchmark values to disentangle a case-mix effect from incorrect coefficients. Am. J. Epidemiol. 2010;172:971-80.

8. Hickey $G L$, et al. Dynamic trends in cardiac surgery: why the logistic euroscore is no longer suitable for contemporary cardiac surgery and implications for future risk models. Eur. J. Cardio-thoracic Surg. 2013;43: 1146-52.

9. Debray TPA, et al. A guide to systematic review and meta-analysis of prediction model performance. BMJ. 2017;356.

10. Davis SE, Lasko TA, Chen G, Siew ED, Matheny ME. Calibration drift in regression and machine learning models for acute kidney injury. J. Am. Med. Informatics Assoc. 2017;24:1052-61.

11. Nashef SAM, et al. European system for cardiac operative risk evaluation (EuroSCORE). Eur. J. Cardio-thoracic Surg. 1999;16:9-13.

12. Luijken $\mathrm{K}$, et al. Changing predictor measurement procedures affected the performance of prediction models in clinical examples. J. Clin. Epidemiol. 2020;119:7-18.

13. van Houwelingen HC, Thorogood J. Construction, validation and updating of a prognostic model for kidney graft survival. Stat. Med. 1995;14:1999-2008.

14. Janssen KJM, Moons KGM, Kalkman CJ, Grobbee DE, Vergouwe Y. Updating methods improved the performance of a clinical prediction model in new patients. J. Clin. Epidemiol. 2008;61:76-86.

15. Debray TPA, Koffijberg H, Vergouwe Y, Moons KGM, Steyerberg EW. Aggregating published prediction models with individual participant data: a comparison of different approaches. Stat. Med. 2012;31:2697-712.

16. Martin GP, Mamas MA, Peek N, Buchan I, Sperrin M. A multiple-model generalisation of updating clinical prediction models. Stat. Med. 2018;37:1343-58.

17. Riley RD, et al. External validation of clinical prediction models using big datasets from e-health records or IPD meta-analysis: opportunities and challenges. BMJ. 2016;353:27-30.

18. Debray TPA, Riley RD, Rovers MM, Reitsma JB, Moons KGM. Individual participant data (IPD) meta-analyses of diagnostic and prognostic modeling studies: guidance on their use. PLoS Med. 2015;12:1-12.

19. Martin GP, Mamas MA, Peek N, Buchan I, Sperrin M. Clinical prediction in defined populations: a simulation study investigating when and how to aggregate existing models. BMC Med. Res. Methodol. 2017;17:1.

20. Hippisley-Cox J, et al. Derivation and validation of QRISK, a new cardiovascular disease risk score for the United Kingdom: prospective open cohort study. Br. Med. J. 2007;335:136-41.

21. Hippisley-Cox J, et al. Predicting cardiovascular risk in England and Wales: prospective derivation and validation of QRISK2. BMJ. 2008;336:1475-82.

22. Nashef SAM, et al. Euroscore II. Eur. J. Cardio-thoracic Surg. 2012;41:734-745.

23. Raftery AE, Kárný M, Ettler P. Online Prediction Under Model Uncertainty via Dynamic Model Averaging: Application to a Cold Rolling Mill. Technometrics. 2010;52(1):52-66. https://doi.org/10.1198/TECH.2009.08104.

24. Jenkins DA, Sperrin M, Martin GP, Peek N. Dynamic models to predict health outcomes: current status and methodological challenges. Diagnostic Progn. Res. 2018;2:23.

25. Fan J, Zhang W. Statistical methods with varying coefficient models. Stat Interface. 2008;1:179-95. 
26. Hoover DR, Rice JA, Wu CO, Yang L-P. Nonparametric smoothing estimates of time-varying coefficient models with longitudinal data. Biometrika. 1998; 85:809-22.

27. Mccormick TH, Raftery AE, Madigan D, Burd RS. Dynamic logistic regression and dynamic model averaging for binary classification. Biometrics. 2012;68:23-30.

28. Su TL, Jaki T, Hickey GL, Buchan I, Sperrin M. A review of statistical updating methods for clinical prediction models. Stat Methods Med Res. 2016:1-16. https://doi.org/10.1177/0962280215626466.

29. Hickey $\mathrm{GL}$, et al. Dynamic prediction modeling approaches for cardiac surgery. Circ. Cardiovasc. Qual. Outcomes. 2013;6:649-58.

30. Halabi S, et al. Updated prognostic model for predicting overall survival in first-line chemotherapy for patients with metastatic castration-resistant prostate cancer. J. Clin. Oncol. 2014;32:671-7.

31. Dawid, A. Present position and potential developments: some personal views: statistical theory: the prequential approach Author ( S): A . P . Dawid Source: Journal of the Royal Statistical Society. Series A ( General ), Vol . 147, No . 2, The 150th Annivers. J. R. Stat. Soc. Ser. A 147, 1984 278-292.

32. Lenert, M. C., Matheny, M. E. \& Walsh, C. G. Prognostic models will be victims of their own success, unless.... J. Am. Med. Inform. Assoc. 2019;26: 1645-1650.

33. Friedman $\mathrm{CP}$, Rubin JC, Sullivan KJ. Toward an information infrastructure for global health improvement. Yearb. Med. Inform. 2017;26:16-23.

34. Adibi, A., Sadatsafavi, M. \& loannidis, J. P. A. Validation and utility testing of clinical prediction models. JAMA 2020; 2004.

35. Booth, S., Riley, R. D., Ensor, J., Lambert, P. C. \& Rutherford, M. J. Temporal recalibration for improving prognostic model development and risk predictions in settings where survival is improving over time. Int. J. Epidemiol. 2020; 1-10. doi:https://doi.org/10.1093/ije/dyaa030.

36. Vergouwe $Y$, et al. A closed testing procedure to select an appropriate method for updating prediction models. Stat. Med. 2017;36:4529-39.

37. Altman DG, Royston P. What do we mean by validating a prognistic model? Stat. Med. 2000;19:453-73.

\section{Publisher's Note}

Springer Nature remains neutral with regard to jurisdictional claims in published maps and institutional affiliations.

Ready to submit your research? Choose BMC and benefit from:

- fast, convenient online submission

- thorough peer review by experienced researchers in your field

- rapid publication on acceptance

- support for research data, including large and complex data types

- gold Open Access which fosters wider collaboration and increased citations

- maximum visibility for your research: over $100 \mathrm{M}$ website views per year

At $\mathrm{BMC}$, research is always in progress.

Learn more biomedcentral.com/submissions 